\title{
Conforto Térmico nas Edificações: Materiais e Técnicas Construtivas. Um estudo comparativo entre a cidade de Ouro Preto - Brasil e Porto - Portugal.
}

\author{
Thermal Comfort in Buildings: Materials and Construction Techniques. \\ A comparative study between the city of Ouro Preto - Brazil and Porto - \\ Portugal.
}

\section{Maria Cláudia Lima da Cruz *}

\begin{abstract}
*Graduada em Arquitetura e Urbanismo na Pontifícia Universidade Católica (MG). PósGraduações: Conforto e Edificações Sustentáveis na Universidade Gama Filho (RJ); Engenharia de Segurança do Trabalho (Centro Universitário FIPMoc (MG); Master em Arquitetura e lluminação no Instituto de Pós-Graduação e Graduação (MG); Mestre em Engenharia Civil na Universidade Fernando Pessoa (Porto, Portugal). Docente na Faculdades Santo Agostinho (MG): disciplinas de Conforto Ambiental, de projetos; e na instituição Faculdades Integradas do Norte de Minas (MG), disciplinas de Materiais de Construção e projetos. Atua em projetos residenciais, de interior, comerciais, área de saúde e incêndio.
\end{abstract}

usjt • arq.urb • número 27 | janeiro - abril de 2020

\section{Abstract}

presente trabalho tem a intenção de tratar as questões relacionadas aos estudos de conforto ambiental, analisando o comportamento térmico das edificações no sentido de estudar soluções arquitetônicas através do uso de técnicas construtivas e materiais que propõem minimizar o desconforto térmico no ambiente construído. A pesquisa tem como objetivo identificar e analisar a presença de calor ou frio, desconforto térmico nas edificações e localizar as possíveis características construtivas que são responsáveis por estes fenômenos. Para um melhor entendimento do assunto foram feitos estudos comparativos de conforto térmico relacionado com as edificações e seus materiais componentes entre a cidade de Ouro Preto - Minas Gerais - Brasil e Porto - Portugal, edifícios escolhidos pela importância histórica nos dois países e considerados bens do patrimônio da humanidade. Dentro desse contexto foi realizada uma revisão bibliográfica de diversos trabalhos sobre a arquitetura local e os recursos naturais de conforto ambiental buscando conhecer e relatar a importância da utilização correta dos materiais e das técnicas como uma estratégia eficiente na busca do conforto.

Palavras-chave: Arquitetura, Edifício, Conforto Ambiental.
The present work intends to address the issues related to environmental comfort studies, analyzing the thermal behavior of buildings in order to study architectural solutions through the use of construction techniques and materials that propose to minimize thermal discomfort in the built environment. The research aims to identify and analyze the presence of heat or cold, thermal discomfort in buildings and locate the possible constructive characteristics that are responsible for these phenomena. For a better understanding of the subject were made comparative studies of thermal comfort related to the buildings and their component materials between the city of Ouro Preto - Minas Gerais - Brazil and Porto - Portugal, buildings chosen by the historical importance in both countries and considered heritage property. of humanity. Within this context, a bibliographic review of several works on local architecture and natural resources of environmental comfort was performed, seeking to know and report the importance of the correct use of materials and techniques as an efficient strategy in the search for comfort.

Keywords: Architecture, Building, Environmental Comfort. 


\section{Introdução}

M a presença cada vez mais evidente do aumento da temperatura nos centros urbanos e, dentro das edificações, o que pode decorrer do uso inadequado ou ineficiente de materiais específicos que garantam o conforto térmico dos ambientes. Além de os fenômenos naturais terem sofrido diversas alterações, como por exemplo, nos níveis de temperatura do globo terrestre, o homem sofre hoje as consequências de suas próprias ações. As cidades sentem os resultados destas atitudes e tornam-se verdadeiras estufas, em determinadas áreas, especialmente onde se concentram os centros urbanos e a maior parte das edificações.

Nesse sentido, esta pesquisa justifica-se pelo fato de procurar estudar a importância do uso de especificações adequadas na elaboração de projetos para a melhoria da qualidade dos ambientes, bem como a compreensão sobre os fatores, técnicas construtivas e materiais que influenciaram na configuração espacial das áreas críticas em termos de conforto térmico, ao se comparar o comportamento de uma edificação da cidade de Ouro Preto, no Brasil e outra no Porto, em Portugal, nos aspetos históricos, arquitetônicos e orientação solar semeIhantes, a fim de que esses elementos contribuam para um procedimento adequado, visando o conforto e, consequentemente, melhor qualidade de vida. A provável resposta à análise de comportamento térmico nos ambientes em estudo, após avaliados com métodos, parâmetros climáticos das duas regiões e aplicação de prática com um programa específico de engenharia e arquitetura, com a criação de modelos digitais em três dimensões e as características formais, materiais e construtivas, mais a medição de resultados, comprovariam a influência das decisões projetuais nas sensações de conforto presentes em cada edificação.

Para isso, estudos de caso serão utilizados, como forma de entender os processos construtivos de países com histórias diferentes, porém, com laços de influências marcantes na colonização espacial; também como isso pode ser determinante aos fatores relacionados à presença de conforto nos ambientes, quanto à temperatura ambiente, ventilação natural e soluções técnicas. Foca-se num estudo comparativo entre Brasil e Portugal, por se tratar de países com uma história em comum. Afinal, Portu- 
gal tendo sido o descobridor, e um dos colonizadores do Brasil, exerceu e exerce forte influência na cultura e na arquitetura deste local. Pretende-se, pois, entabular este paralelo entre dois países tão distantes mas tão próximos, outrossim, pelo fato histórico que os envolve sem olvidar a relevância do tema sustentabilidade no contexto atual do planeta.

\section{Objetivos}

O presente artigo tem como objetivo identificar e analisar as diferentes sensações térmicas das construções e edificações situadas nas cidades de Ouro Preto - MG - Brasil, e Porto, em Portugal, com foco nos materiais utilizados na região e a influência destes nos acontecimentos relacionados à falta de conforto térmico, à questão da eficiência energética, os impactos ambientais e a sustentabilidade, buscando localizar as possíveis causas das características construtivas e dos materiais responsáveis por estes fenômenos. Assim, diagnosticarse-á se o uso das técnicas e dos materiais nas edificações das duas cidades realmente reflete na satisfação dos usuários, por exemplo, no ambiente de convívio. Para tal, irá se comparar as variações da temperatura nas edificações, analisando-se e se estabelecendo um paralelo nas diferentes situações vividas em cada sítio.

\section{Metodologia}

A metodologia de pesquisa foi traçada na busca da operacionalização dos objetivos propostos neste estudo, baseada em levantamentos e pesquisa bibliográfica com consulta a livros, artigos publicados em periódicos e eventos científicos, relatórios, além de visitas a secretarias do patrimônio histórico de cada localidade e consulta de sites oficiais de órgãos governamentais.

Serviram aos propósitos deste trabalho, a busca de documentação indireta, feita por meio da pesquisa bibliográfica e documental, a coleta de dados feita nos órgãos referenciais da cidade, bem como análise de materiais utilizados nas construções e edificações pesquisadas e o uso de programa apropriado, como o Archicad, para averiguar e conferir o desempenho térmico das edificaçãoes e seus impactos ambientais por meio de relatórios gerados pelo programa, a fim de concluir como se dá o conforto térmico, analisados o clima e os materiais empregados nas diferentes situações.

A pesquisa bibliográfica teve como base livros e revistas de redes eletrônicas, por meio de fontes primárias e secundárias, com o objetivo de reportar as experiências, confrontando pensamentos variados e estudos do lugar, para poder organizar um só pensamento que contemple instrumentos para buscar a solução a problemática em questão. 


\section{Breve histórico da arquitetura brasileira e portuguesa}

A arquitetura brasileira desenvolveu grande parte de sua história utilizando a herança dos europeus. Território conquistado e inicialmente habitado por povos indígenas, que só possuíam a arquitetura própria e principalmente a habitacional, integra e conquista uma nova cultura. Consequentemente, eis uma nova arquitetura, com a chegada dos portugueses, que, mesmo ao longo de séculos influenciando bastante, não foi suficiente para criar características ou estilos únicos de arquitetura, uma vez que a construção civil se colocou sempre como expressão mais livre e sem compromissos, visando necessidades básicas e o conforto, de forma geral, abrindo-se ao improviso e a materiais locais, e mesmo a alguma influência de hábitos indígenas, decorrendo daí, a parte mais diversificada do conjunto.

Por ser a arquitetura brasileira, em grande parte, importada de Portugal, as construções tendiam a seguir alguns padrões com relação à posição nos terrenos. Elas eram construídas nos limites frontais e laterais, tornando os elementos de vedação como as paredes, também elementos de sustentação das coberturas e que acabavam por definir os limites das vias públicas.

Reis Filho (1997, p.24) afirma que:
[...] a uniformidade dos terrenos correspondia à uniformidade dos partidos arquitetônicos: as casas eram construídas de modo uniforme, em certos casos, tal padronização era fixada nas Cartas Régias ou em posturas municipais. Dimensões e números de aberturas, alturas dos pavimentos $\mathrm{e}$ alinhamentos com as edificações vizinhas foram exigências correntes do século XVIII. Revelam uma preocupação de caráter formal, cuja finalidade era, em grande parte, garantir para as vias e cidades brasileiras uma aparência portuguesa.

O Brasil era visto como um bem a ser explorado, todavia, a colonização também expressou a concepção de uma nova população, no início meio flutuante, mas crescentemente enraizada. Algumas características típicas deste período se definiram pelo estilo barroco, que preponderou durante boa parte do período colonial, assimilando, em sua fase derradeira, linhas do rococó. O estilo encontrou sua revelação mais conveniente na arquitetura da região de Minas Gerais, ponderada por muitos autores como a principal composição erudita tipicamente brasileira.

Na história da arquitetura mineira, pode se perceber que foram as irmandades as grandes impulsionadoras da arquitetura deste local. Segundo Lemos (1979), as construções religiosas, como as igrejas, em geral bastante ricas, ostentavam importância ou prestígio maior para valorizar a religião e influenciar na formação das cidades. Para ele, a grande beneficiária dessa emulação foi a arquitetura barroca, 
cuja importância chama a atenção de todos, situando-nos como os donos de um passado artístico destupendo e imponente no panorama da arte universal.

Tanto a arquitetura colonial, como as outras que surgiram depois, não tiveram apenas "estilos e tendências à moda fundamentalmente europeia" (ZARROQUINO, 2006, p. 21), ofereciam características referentes aos locais em que estavam inseridas. Na fase colonial, a herança portuguesa é facilmente notada nas edificações residenciais e nos traçados das vias públicas.

As várias influências artísticas contribuiram com a constituição do barroco no cenário brasileiro. Foi atráves do barroco mineiro, na figura de Antônio Francisco Lisboa, conhecido como Aleijadinho, nascido em 1730 na cidade de Ouro Preto - Minas Gerais, que a imagem barroca do Brasil ficou mais conhecida. Nesse sentido, "cresceu e aprendeu a maneijar toscos instrumentos de sua profissão...onde tomou conhecimento dos elementos da linguagem barroca, ou rococó..." (LEMOS, 1979, p.10).

Em se tratando de materiais para a confecção das peças artísticas, os artistas mineiros tiveram que improvisar, já que nem sempre podiam desfrutar dos melhores recursos vindos de Portugal, como registrou o historiador Arno Wehling et al (1994, p.284):
[...] Havia dificuldade para a importação de materiais da metrópole - a ausência de azulejos provocou prodígios de improvisação nas decorações. Também a quantidade de artífices locais brancos, mulatos e negros alforriados - favorecia as inovações e o uso de material da terra. A escultura em pedra-sabão é o melhor exemplo disso.

Foram usados, inicialmente, na arquitetura mineira, as técnicas da taipa-de pilão e pau-a-pique, que consistem em sistemas utilizados tanto nos tempos da colônia como ainda hoje em construções rurais, devido a suas qualidades - baixo custo (todos os materiais são naturais), resistência e durabilidade, normalmente feitos amassando com um pilão o barro colocado em formas de madeira, os taipais, semelhantes às formas de concreto utilizadas hoje.

Os taipais ou as tábuas laterais de madeira, fixados com cunhas, em baixo, e um torniquete em cima; de rápida construção, utilizavam-se materiais abundantes na colônia: barro e madeira. De acordo com Vasconcelos (1979, p. 45):

A taipa de pilão é o sistema em que as paredes são maciças, constituídas apenas de barro socado, tornando-se monolíticas, por assim dizer, depois de terminadas e raramente incluindo em sua espessura reforços longitudinais de madeira. A técnica de sua execução consiste em armar formas de madeira - denominadas taiapais, como se faz ainda hoje com o concreto, mantendo-as em sua posição por meio de travessas e paus a prumo. Dentro delas é colocado o barro já bem amassado em camadas relativas à largura das tábuas. Em seguida é este barro comprimido 
com um pilão ou com auxílio dos pés, de modo a obter maior consistência da massa.

Outra técnica utilizada na arquitetura mineira semelhante a taipa de pilão é o adobe, que segundo descrição de Vasconcelos (1979), consistem em paralelepípedos de barro, que diferem dos tijolos pelo fato de não serem cozidos no forno. São compactados manualmente em formas de madeira e postos a secar na sombra durante um certo número de dias e depois ao sol. Ele ainda descreve que o barro deve conter uma porcentagem de argila e areia e, também, fibras vegetais ou estrume de boi para uma melhor consistência dos blocos. São assentados e emboçados com barro, podendo receber reboco de cal e areia.

A alvenaria de pedra foi adotada a seguir, sendo esse o material que conferia mais resistência aos muros, razão por que era utilizada nas fortificações, igrejas monumentais e nas construções oficiais. As pedras utilizadas eram calcárias, arenitos ou pedra de rio e granitos, e mesmo a pedrasabão. As argamassas eram cal e areia, mais resistentes, ou o barro e tijolos de adobe nas paredes, possibilitando construções maiores e a inclusão de madeiramento para pisos e tetos. Já "as construções em pedra seca ou com argamassa surgiram devagar... no começo, principalmente para construir embasamentos de estruturas mais complexas de madeira", (LEMOS, 1979, p. 84 a 86).
Estes sistemas já eram igualmente utilizados em Portugal, há séculos, alterando algumas técnicas e materiais das construções em função das características locais de cada país e região específica. Entabulando uma articulação histórica entre os dois países, nota-se que a influência da descoberta do Brasil por Portugal trouxe características arquitetônicas e usos de soluções construtivas semelhantes, com as adaptações necessárias em função da posição terrestre de cada localidade e, consequentemente, diferenças climáticas.

A arquitetura em Portugal foi influenciada, como na maioria das pátrias europeias, pelos movimentos culturais e estéticos que caracterizaram as várias épocas da História da Arte, o que procedeu numa vasta herança patrimonial. Refere-se as práticas da arquitetura realizada no território português, desde antes da fundação do país no século XII. De acordo com Barreira (2003), a Arquitetura de Portugal, assim como todos os aspetos da cultura local, se pauta pela história do país e os vários povos que se instalaram e influenciaram o território português atual. Entre as principais manifestações locais da arquitetura portuguesa estão a manuelina, a versão portuguesa do estilo gótico; e do estilo pombalino, uma mistura do barroco tardio e neoclassicismo que se desenvolveu depois do_Grande Terremoto de Lisboa, de 1755 . 
Como discorre Fernandes (2000), a arquitetura portuguesa tem suas originalidades e especificidades em termos materiais, como em manifestações ibéricas, através do nortenho granito, o xisto do centro e Sul, a área estremenha do calcário, o barro a taipa e o adobe meridionais.

Em relação aos materiais utilizadas nas edificações portuguesas, Santos (2013) diz que estão relacionados com a composição da fachada, com o desenho e o arranjo dos seus elementos e com a expressão, qualidade e acabamento da obra. Ele completa que a decisão entre blocos de pedra ou alvenaria rebocada mostra o sentido e a medida do apropriado para cada edifício em cada uma das suas partes. Portanto, a escolha dos materiais está associada a um compromisso entre a finalidade da obra, os recursos técnicos existentes, os meios disponíveis e o acesso a esses materiais; no entanto, o fator geográfico e a compreensão da obra no lugar são decisivos para o entendimento da expressão dos edifícios e da leitura de conjunto.

Em análises feitas pela autora de forma mais específica em sítio na cidade do Porto, percebeu-se um pouco das técnicas construtivas e dos materiais usados nas construções antigas e atuais através de visitas feitas em obras de reabilitação de prédios históricos. Foi possível notar que as construções, em sua maioria, são basicamente de granito, um material que faz parte do acervo de materiais regionais, presente em abundância nesta região norte de Portugal. Como nesta parte do país o clima varia muito devido às mudanças das estações do ano, tendo tanto verões quanto invernos rigorosos e bem marcados por características típicas e predominantes de cada estação, e já se preocupando com esse fator, as construções contam com técnicas de elaboração bem específicas e adequadas a estas mudanças de clima no decorrer do ano. Muitas delas costumam ser projetadas e construídas com o uso de paredes duplas e com algum material isolante termo acústico apropriado, cuja finalidade é obter conforto tanto no verão quanto no inverno.

Diante de informações obtidas através do Porto Vivo - SRU da cidade do Porto, após as vistorias a todas as parcelas da Unidade de Intervenção realizada nesta região específica, inferiu-se que maioritariamente os edifícios mantêm o sistema construtivo tradicional: estruturas de alvenaria e de madeira, coberturas revestidas com telha cerâmica, e revestimentos à base de madeiras, rebocos de gesso e cal. As estruturas verticais são predominantemente as paredes de meação em alvenaria de pedra, nas quais se apoiam os vigamentos de madeira dos pavimentos. Nas fachadas, preponderam aparelhos em cantaria/alvenaria com reboco pintado ou ladriIhos cerâmicos. Os vãos são emoldurados a cantaria de granito. As estruturas horizontais são, na maioria das vezes, constituídas por vigamento de madeira encastradas nas paredes de meação, onde se assenta o soalho. Ainda de acordo com as análises pelo Porto Vivo, as caixas de escadas estão no cen 
tro dos lotes, numa posição perpendicular às paredes de meação e são geralmente constituídas e revestidas a madeira. As coberturas são inclinadas, revestidas a telha cerâmica do tipo "Marselha" à cor natural, geralmente de quatro águas, assentes em estrutura de madeira. As edificações possuíam também claraboias, normalmente posicionadas em cima das caixas de escadas, com o objetivo de privilegiar a entrada de iluminação natural na edificação.

Segundo Moreira (2009) nas estruturas dos edifícios antigos as paredes exteriores, também denominadas paredes-mestras, acumulam a função resistência e proteção contra os agentes climáticos e as ações externas. Já as paredes interiores, designadas por frontais, de acordo com as técnicas herdadas do período pombalino, taipas ou tabiques, são vocacionadas para a redistribuição de esforços, sendo por isso dispostas segundo as duas direções ortogonais dos edifícios. Ela ainda explica que, à semelhança dos elementos estruturais anteriores, também na execução dos pavimentos a madeira constitui o principal material. Utilizada tanto nos vigamentos que compõem a estrutura do pavimento, quanto nos soalhos que se caracterizam como o revestimento, a madeira surge como o material preponderante, uma vez que confere ao pavimento a segurança necessária para cumprir as funções a que se destina.
Sobre as coberturas dessas edificações, Moreira (2009) ainda completa que são constituídas por uma estrutura principal, da qual fazem parte as asnas e os elementos de ligação das mesmas, por uma outra secundária, assente sobre a principal e formada pelos elementos de suporte do revestimento e, por último, pelo revestimento, geralmente de telha, que se encaixa entre as ripas da estrutura secundária.

Segundo o Guia de Termos de Referência para o Desempenho Energético- Ambiental do Porto Vivo Secretaria de Reabilitação Urbana, Portugal dispõe de uma regulamentação energética térmica que se refere às potencialidades da arquitetura e da construção, que vem dos anos 90, o RCCTE - Regulamento das Características de Comportamento Térmico dos Edifícios que, como seu nome já diz, interpela o próprio edifício como sistema energético para o conforto. Ainda de acordo com este Guia, mais tarde, em 1996, foi aprovado o RSECE - Regulamento dos Sistemas Energéticos de Climatização em Edifícios, focalizando nos sistemas auxiliares para a climatização. Ambos os regulamentos atualizados em 2006, acham-se em plena aplicação sob o SCE - Sistema Nacional de Certificação Energética e da Qualidade do Ar Interior dos Edifícios. Com isso, espera-se que em Portugal os edifícios tenham eficiência no seu próprio desempenho, reduzindo a necessidade de aquecimento pelo isolamento térmico e melhorando as condições de arrefecimento pelo recurso ao sombreamento e a circulação do ar, 
bem como favorecendo o conforto graças à inércia térmica. Este guia deixa claro que estas intervenções são geridas pelo ângulo da energia, embora respondam genuinamente também pelo lado do conforto, do bem-estar e da salubridade.

\section{Aspectos do clima e conforto ambiental}

$\mathrm{Na}$ definição mais simplificada do autor Borba (2005) , o termo clima refere-se a um conjunto de dados (temperatura, pressão, umidade) a respeito das condições atmosféricas de um determinado local, durante um período cronológico específico. $\mathrm{O}$ tipo de clima de um determinado local depende de uma série de fatores, como latitude, altitude, relevo e radiação solar. Até mesmo a presença do ser humano pode alterar o clima. A caracterização do clima de uma região é uma representação do comportamento médio baseada em dados diários da condição atmosférica. O clima do Brasil é diversificado em consequência de fatores variados, como a fisionomia geográfica, a extensão territorial, o relevo e a dinâmica das massas de ar.

Segundo Mascaró (1996), o clima urbano constitui um sistema que abrange o clima de um determinado espaço e sua urbanização, sendo assim, é importante se observar a morfologia urbana, o entorno da edificação e a influência da topografia do lugar para compor o microclima. Vale ressaltar que vários fatores influem diretamente no microclima do local, assim como: a topografia, a vegetação e a superfície do solo natural ou construído.
A aplicação da climatologia aos seres vivos é denominada bioclimatologia e, de acordo com Gonçalves e Graça (2004) a arquitetura bioclimática pode ser definida como uma arquitetura, que na sua concepção, aborda o clima como uma variável importante do projeto e tem a interação entre o sol e o edifício como fator fundamental. Eles afirmam ainda:

As estratégias que têm em atenção as condições climáticas do local e da sua interação com o clima, proporcionando a adequação do edifício ao clima, designam-se geralmente por Estratégias Bioclimáticas. São no fundo regras gerais que se destinam a orientar a concepção do edifício tirando partido das condições climáticas de cada local. (GONÇALVES e GRAÇA, 2004, p.10)

Uma análise bioclimática é conveniente quando se ativa em projetos arquitetônicos que procurem evitar falha de adequação da obra ao contexto do lugar. A arquitetura que se usa em determinada localidade pode não se adequar à realidade de outro clima diferenciado, porque tanto o posicionamento do edifício, a forma, como os materiais a serem utilizados devem ser pensados levando sempre em consideração as condições climáticas e o entorno imediato do local onde será inserida determinada construção. "A Arquitetura, como uma de suas funções, deve oferecer condições térmicas compatíveis ao conforto térmico humano no interior dos edifícios, sejam quais forem as condições climáticas externas". (FROTA e SCHIFFER, 2001, p.15.) 
O Brasil é um país nomeado tropical, todavia apresenta uma variação climática considerável, pois, por ter uma vasta extensão territorial e várias configurações topográficas, em toda sua área apresenta climas muito diferenciados em suas regiões e estados. Assim, de acordo com o Instituto Nacional de Meteorologia (INMET), o clima do Brasil é diversificado em consequência destes fatores variados, como a fisionomia geográfica, a extensão territorial, o relevo e a dinâmica das massas de ar. Este último fator é significativo visto que atua diretamente tanto na temperatura quanto na pluviosidade, provocando as diferenças climáticas regionais.

A cidade de Ouro Preto está localizada numa região onde o clima predominante é o tropical de altitude (Cwb) de acordo com a classificação climática de Köppen-Geiger), característico das regiões montanhosas, com chuvas durante os meses de outubro a abril e geadas ocasionais em junho e juIho. De acordo com vivência na cidade em diversas épocas do ano, fica fácil notar que o clima de Ouro Preto é ameno na maioria das vezes, não apresentando calor excessivo e tampouco frio exagerado.

O clima em Portugal é mediterrânico, Csa no sul e Csb no norte, de acordo com a classificação climática de Köppen-Geiger. Portugal é um dos países europeus de temperaturas mais amenas, em acordo ao Instituto Português do Mar e da Atmosfera
(IPMA). A análise espacial baseada nas normas de 1961/90 mostra a temperatura média anual, a variar entre cerca de $7^{\circ} \mathrm{C}$ nas terras altas do interior norte e centro e cerca de $18^{\circ} \mathrm{C}$ no litoral sul.

A cidade do Porto tem um clima mediterrânico do tipo Csb de acordo com a classificação climática de Köppen-Geiger. No Inverno, as temperaturas variam entre os $5^{\circ} \mathrm{C}$ e os $14^{\circ} \mathrm{C}$ raramente descendo abaixo dos $0{ }^{\circ} \mathrm{C}$. Durante esta estação, períodos chuvosos alternam com dias mais frios e de céu limpo. No Verão, as temperaturas variam entre os $15^{\circ} \mathrm{C}$ e os $25^{\circ} \mathrm{C}$ podendo ocasionalmente atingir ou mesmo ultrapassar os $35^{\circ} \mathrm{C}$ nos meses de julho ou agosto.

O espaço urbano, de uma forma geral, deve suprir as necessidades de bem estar e consumo, no entanto não oferece, muitas vezes, condições ambientais adequadas para que seus habitantes tenham qualidade de vida. Alguns parâmetros que indicam qualidade de vida vêm sendo discutidos e, o conforto ambiental sempre está associado a estes parâmetros. Beraldo (2006), afirma que o clima e as estações do ano influenciam na sensação de conforto térmico. Porém, apesar de possível o controle do clima interno do edifício, o externo não pode ser controlado, devendo ser então minimizado através da envolvente do edifício e da interação deste com o meio ambiente.

Lamberts (2011), define Conforto Térmico como estado mental que expressa a satisfação do homem 
com o ambiente que o circunda. Portanto, segundo a NBR 15.220 - Desempenho térmico das edificações (ABNT, 2005), o Conforto Térmico é a satisfação psicofisiológica de um indivíduo com as condições térmicas do ambiente. A importância de se estudar este aspeto da natureza juntamente com o desenvolvimento humano está diretamente relacionada à satisfação do homem ou seu bem estar em se sentir termicamente confortável, ao seu desempenho - melhor rendimento nas tarefas em geral e também a conservação de energia.

$\mathrm{Na}$ atualidade, as edificações, especialmente no Brasil, ao contrário do que se pode ver em Portugal, até mesmo por causa de normas específicas e vigentes em cada país, descuida-se das questões relacionadas à térmica dos ambientes. Carlos Lemos (1979 p.17) afirma que hoje há um certo descuido com os isolamentos térmicos, havendo abuso do uso de panos de envidraçados logo anulados por cortinas, agravando-se o agravado, com ventilações sempre precárias, e ainda acrescenta que "o progresso foi mais teórico que prático, porque os benefícios do ar condicionado, das calefações, dos aquecimentos, dos controles eletrônicos, das células fotelétricas e de todo equipamento eletrodoméstico na verdade não é acessível a todos"(LEMOS, 1979, p.17). Sendo assim, é notória a diferença das construções atuais em relação ao conforto térmico, que se deve, principalmente, ao fato de existir mecanismos artificiais com facilidade, provocando este descaso na sustentabilidade da arquitetura.

\section{Estudo de Caso - comparativo entre a cidade de Ouro Preto - Brasil e Porto - Portugal}

Este estudo comparativo se faz importante para a presente pesquisa com o intuito de tentar esclarecer se há realmente diferenças de temperatura relacionadas com as adaptações em termos de materiais, advindas das influências portuguesas na arquitetura brasileira, usando como base as edificações situadas nas cidades do Porto, em Portugal e em Ouro Preto, no Brasil.

Para se comparar as cidades propostas como estudo do presente trabalho é importante salientar primeiro o posicionamento das duas cidades no globo terrestre, visto que Porto - Portugal se localiza no hemisfério norte e Ouro Preto - Brasil, no hemisfério sul, o que garante as diferenças marcantes nas estações do ano, bem como no próprio comportamento climático de cada região que se mostra diferente, o que não exclui a possibilidade de tratamentos arquitetônicos, no que diz respeito tanto ao uso de materiais quanto a técnicas construtivas adotadas em cada lugar, serem similares em algumas situações específicas. Analisando as construções da cidade do Porto, percebe-se um cuidado maior com o uso de técnicas e materiais buscando um conforto térmico nas edificações, talvez por causa de invernos rigorosos presentes no local ou pela evolução do mercado internacional. Faz-se possível notar nitidamente a preocupação com o clima dentro do espaço interno, quando se percebe as construções 
feitas com paredes duplas e o uso de materiais que contribuem para este fim.

O Porto é a segunda maior cidade e o quarto município mais populoso de Portugal, situada na região norte do país e capital da Área Metropolitana do Porto. É ainda uma cidade conhecida mundialmente pelo seu vinho, pelas suas pontes e arquitetura contemporânea e antiga, ademais, o seu centro histórico, classificado como Patrimônio Mundial pela UNESCO.

A outra localidade, Ouro Preto, é um município situado no estado de Minas Gerais, no Brasil. Segundo informação o IBGE (Instituto Brasileiro de Geografia e Estatística), o descobrimento do sítio em que surgiu a Vila Rica, hoje cidade de Ouro Preto, declarada Monumento Nacional por ato do Presidente da República, constitui acontecimento intimamente ligado ao descobrimento das minas de ouro. Em 5 de setembro de 1980, na quarta sessão do Comitê do Patrimônio Mundial da UNESCO, realizada em Paris, Ouro Preto foi declarada Patrimônio Cultural da Humanidade, de acordo com informações da prefeirtura Municipal de Ouro Preto.

Para realização do estudo comparativo faz-se necessária a verificação dos materiais e técnicas construtivas empregadas nas duas edificações, buscando favorecer e garantir o conforto térmico no seu interior, portanto, o aspeto julgado como essencial para estas definições seria o tratamento das envoltórias das construções em estudo.

Na situação analisada nas duas cidades a diferença mais percebida em termos arquitetônicos seria justamente a questão que se refere ao tratamento dessas envolventes das edificações; muitas das técnicas e materiais utilizados em Porto poderiam ser adequadas à cidade de Ouro Preto, mesmo com tantas diferenças climatológicas e culturais entre elas. Para Marian Keeler e Bill Burke (2010 p.126), "o projeto do sistema de vedação externa, ou seja, da pele da edificação, continua sendo fundamental para as edificações dominadas pela carga interna". Ou, seja, é o devido tratamento nos fechamentos das edificações que vai determinar as condições térmicas internas ambientais. Os autores ainda afirmam que "fatores como a orientação das janelas, o projeto da pele da edificação e a seleção dos materiais de construção internos determinam a quantidade de energia necessária para se manter o conforto térmico" (KEELER, BURKE, 2010 p.127). Através de pesquisas realizadas, é clara a diferença destes tratamentos das envolventes dos edifícios nas diferentes localidades analisadas, por exemplo, em Porto a preocupação com o fator de comportamento térmico das construções e mesmo em fases de reabilitações, restaurações e reformas, destacando-se o uso de materiais e técnicas adequadas com esta finalidade. 


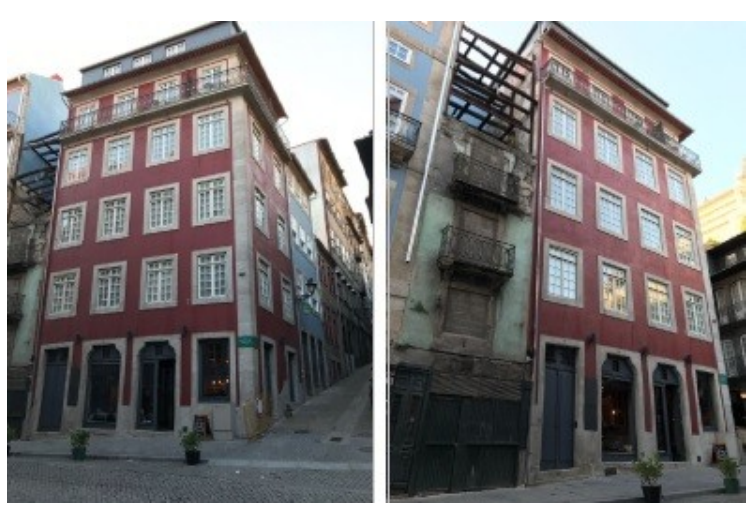

Figura 01 - Vistas da edificação escolhida em Porto. Fonte: Arquivo Pessoal do autor, 2017

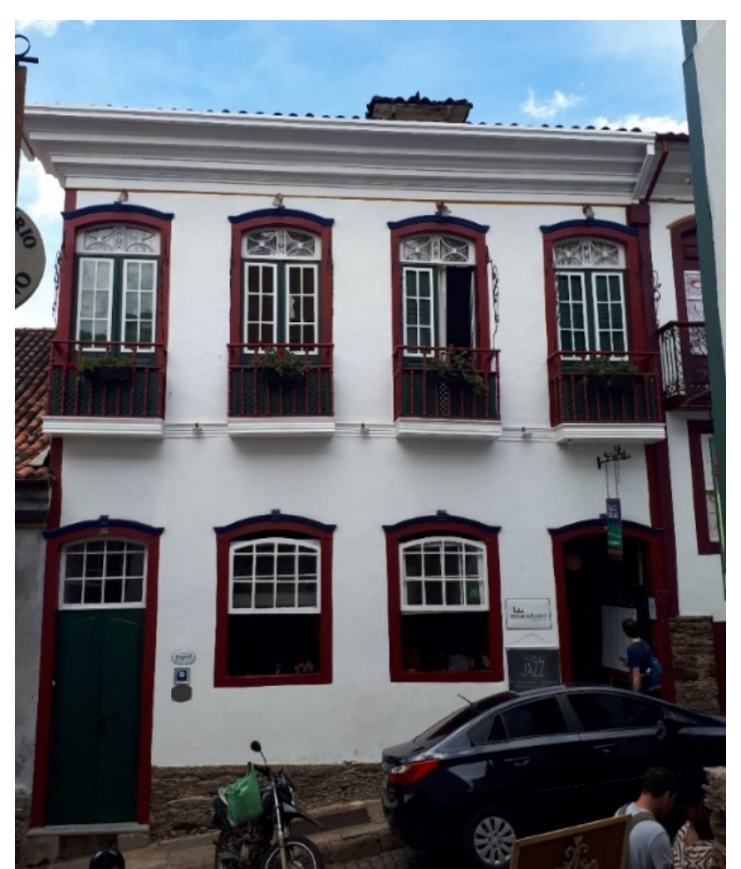

Figura 02 - Vista frontal da edificação escolhida em Ouro Preto. Fonte: Arquivo Pessoal do autor, 2017

usjt • arq.urb • número 27 | janeiro - abril de 2020
A edificação da cidade do Porto em estudo (Figura 01) localiza-se no Quarteirão São João mais precisamente na esquina das Ruas Clube Fluvial Portuense e Rua dos Mercadores. Com base na descrição da documentação Porto Vivo - Sociedade de Reabilitação Urbana, a Rua dos Mercadores que era das ruas mais importantes do burgo medieval devido ao comércio intenso que a caracterizava, acentuado pela ligação direta entre a Porta da Ribeira e a parte alta do burgo.

A edificação escolhida (Figura 02) para estudo e análise de conforto em relação à anterior, situada em Portugal, foi um casarão localizado na cidade de Ouro Preto, estado de Minas Gerais, no Brasil. Esta escolha se deve a alguns fatores julgados colaboradores da pesquisa, como o fato de a cidade de Ouro Preto ter sido uma das primeiras a ser colonizada por portugueses. Com isso em pauta, traz influências na arquitetura e nas formas de construir e gerir as cidades, e, também por esta cidade ser Patrimônio da Humanidade, assim como Porto, carregando importância significativa para a história dos dois países.

\section{Procedimentos e Resultados}

$\mathrm{Na}$ fundamentação desta pesquisa, utilizou-se alguns recursos, para a análise da situação climática de cada edificação, como o estudo das cartas solares em cada localidade, e o programa Archicad (Figuras 03 e 04), com o levantamento do existente referente a cada edificação. Foram introduzidas informações dos projetos, como a localização dos mesmo através do sistema de coordenadas geográficas, dados climáticos, e ainda os dados relacionados à insolação e à ventilação relativos a cada edifício, de acordo com o tipo de clima específico das cidades do Porto e de Ouro Preto, a fim de testar os materiais e as técnicas construtivas das edificações em estudo, com a intenção de demonstrar, através da tecnologia de um programa específico de engenharia e arquitetura, o comportamento e a influência destes materiais com simulações capazes de gerar modelagens reais e relatórios da análise de conforto e eficiência energética de cada prédio.

A partir das investigações e estudos efetuados para a elaboração desta pesquisa, é viável perceber resultados que explicam e exemplificam os fenômenos de comportamento térmico das edificações em diferentes localidades, com aspetos históricos que se completam em função da ligação entre os dois países. Como a cidade do Porto possui, atualmente, normas específicas que qualificam as edificações, no âmbito de conforto, bem como eficiência energética a sua arquitetura se torna mais eficiente em relação à sustentabilidade. Sendo assim, conclui-se que, no Porto, por haver uma preocupação com estes pontos, o uso de materiais e técnicas construtivas são mais adequadas para que o ambiente interno se torne mais agradável, salubre e com requisitos para o conforto ambiental como um todo. Este fato pode ser constatado pelo uso do programa Ar- 


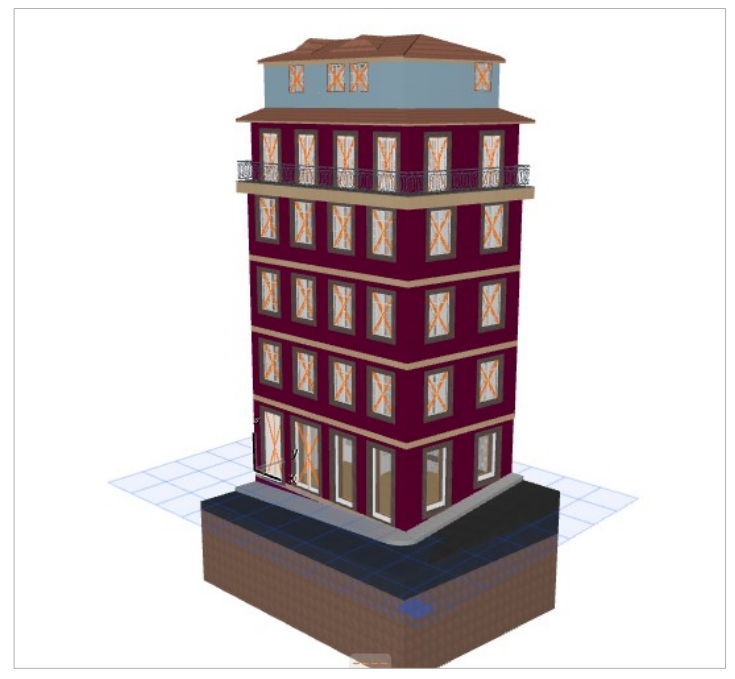

Figura 03 - Modelagem em 3D - Porto. Fonte: Do autor modelado em Archicad

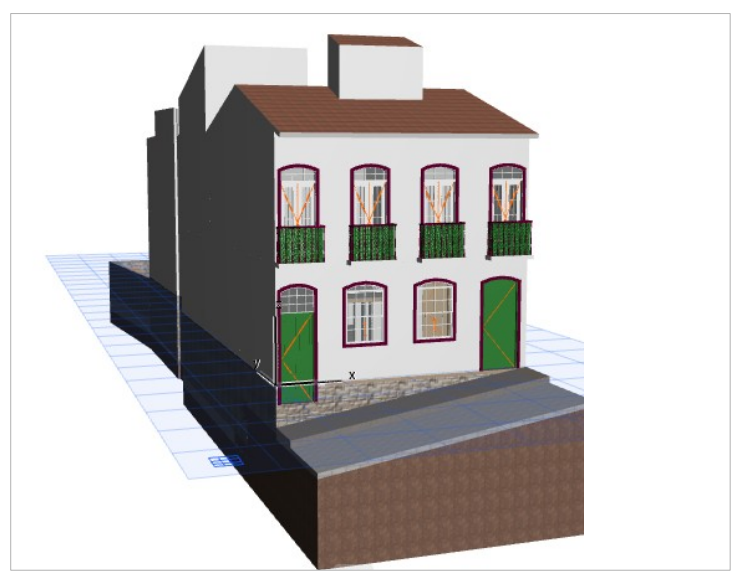

Figura 04 - Modelagem em 3D - Ouro Preto. Fonte: Do autor modelado em Archicad

usjt • arq.urb • número 27 | janeiro - abril de 2020 chicad e Ecodesigner Star, na verificação da modelagem do edifício, usando os parâmetros ambientais locais e as características construtivas, onde se percebe que o impacto ambiental é menor quando comparado ao prédio no Brasil.

Referente à compreensão da componente prática e metodológica desta pesquisa, foi possível concluir que a utilização da ferramenta Archicad e Ecodesigner Star é muito útil e um facilitador para se chegar a resultados procurados na avaliação dos impactos dos materiais e técnicas construtivas na análise das duas situações.

Sendo assim, este trabalho traz um contributo para o aperfeiçoamento do conhecimento, pois trata-se de uma pesquisa objetiva com o intuito de esclarecer como os diferentes materiais e a forma como eles são empregados na arquitetura interferem no conforto térmico das edificações e, consequentemente, no comportamento do usuário e na qualidade de vida dos mesmos.

\section{Conclusão}

Diante do objetivo desse trabalho de abordar o tema conforto térmico e sua relação com a especificação de materiais e as formas de usos dos mesmos dentro das edificações, verificou-se como acontece essa influência e testou este comportamento como forma de demonstrar que, realmente, existe essa relação.
É possível concluir que a sustentabilidade pode ser atingida através de algumas atitudes e decisões projetuais ao nível de soluções e equipamentos especificados, além de empregados de forma correta com análises climáticas, considerando a importância do conforto das construções. É perceptível também que com pequenas ações e usos de critérios apropriados, torna-se possível alcançar avanços que tragam um resultado final satisfatório, principalmente na redução do impacto ambiental.

Através de estudos de campo, e da análise solar de cada região, bem como a pesquisa sobre o clima e a arquitetura local, do auxílio das cartas solares e de programas de modelagens e simulações, permitiu-se concluir que a edificação situada na cidade do Porto em Portugal apresenta um melhor desempenho e conforto térmico, bem como um menor impacto ambiental, se comparado ao edifício situado na cidade de Ouro Preto, no Brasil. Isso porque as decisões projetuais, os materiais e as técnicas construtivas adotadas nas construções portuguesas, oferecem um maior cuidado com as questões de ambientais e de sustentabilidade.

Referente à análise metodológica da parte prática desta pesquisa, foi possível concluir que a utilização das ferramentas Archicad e ecodesigner star é muito útil na reprodução do edifício, tornando o real dentro de uma modelagem e na verificação dos resultados gerados de imediato na comparação entre as duas edificações. 
A elaboração desta pesquisa permitiu concluir, ainda, que é vital a implementação de sistemas de avaliação com estratégias sustentáveis bem definidas nos projetos arquitetônicos e de reabilitação de edifícios históricos, de modo a satisfazer os usuários, buscando uma redução de impactos ambientais e contribuindo, pois, para uma realidade mais condizente à atual situação em que se vive. É preciso estar alerta para reduzir impactos, uma vez que já não se pode continuar utilizando recursos naturais como se fossem bens duráveis e renováveis. Concluindo, atitudes conscientes devem ser tomadas, atingindo todos os âmbitos, inclusive a engenharia, a arquitetura e o urbanismo.

\section{Referências}

AMARAL, Rita "O tombamento de um terreiro de candomblé em São Paulo". In: Comunicações do Iser: Rio de Janeiro, v. 41, 1991.

BARREIRA, Aníbal. e MOREIRA, Mendes. Rumos da História. Porto: Edições ASA, 2003.

BERALDO, Juliano C. Eficiência energética em edifício: avaliação de uma proposta de regulamento de desempenho térmico para a arquitetura do estado de São Paulo. Dissertação de Mestrado, Universidade de São Paulo, São Paulo, 2006.

BORBA, Francisco da Silva. Dicionário Unesp do Português contemporáneo. São Paulo: Unesp, 2005. Disponível em: <https://books.google.com.br/ books $>$. Acesso em 24 fev. 2018.

FERNANDES, José Manuel. Arquitetura Portuguesa - Uma Síntese. Lisboa: Imprensa Nacional Casa da Moeda, 2000.

FROTA, Anésia Barros e SCHIFFER, Sueli Ramos. Manual de Conforto Térmico. 5. Ed. São Paulo: Studio Nobel, 2001.

GONÇALVES, Helder. e GRAÇA, João Mariz. Conceitos Bioclimáticos para os edifícios em Portugal. Lisboa: Editora DGGE/IP 3E, 2004. 
INSTITUTO BRASILEIRO DE GEOGRAFIA E ESTATÍSTICA (IBGE). Portal do IBGE. Disponível em: $\quad<$ https://cidades.bge.gov.br/brasil/mg/ouropreto/historico $>$. Acesso em 18 fev. 2018.

IPMA. Instituto Português do Mar e da Atmosfera. Disponível em: <https://www.ipma.pt/pt/oclima/ normais.clima/>. Acesso em 20/03/2018.

KEELER, Marian e BURKE, Bill. Fundamentos de Projeto de Edificações Sustentáveis. Porto Alegre: Editora Bookman, 2010.

LAMBERTS, Roberto. Conforto e Stress Térmico. Universidade Ferderal de Santa Catarina 2011. LEMOS. Carlos Alberto Cerqueira. Arquitetura Brasileira. São Paulo: Editora Universidade de São Paulo, 1979.

MASCARÓ, Luis. Ambiência Urbana - Urban Environment. Porto Alegre: Ed. Afiliada UFRGS, 1996.

MOREIRA, Marina Fernanda Jesus. Reabilitação de Estrutura de Madeira em Edifícios Antigos Estudo de Caso. Dissertação de Mestrado, Faculdade de Engenharia da Universidade do Porto, 2009.

NBR 15.220. Desempenho Térmico de Edificações, parte 1, 2 e 3. ABNT: Associação Brasileira de Normas Técnicas. Rio de Janeiro, 2005.
PEREIRA, Luís Manuel Pires. Arquitectura portuguesa anos 30-50: atitude e crise de identidade: elementos para a construção de um percurso. Lisboa. Tese de Doutorado, Faculdade de Arquitetura e Artes da Universidade Lusíada de Lisboa, 2011.

PORTO VIVO SRU. Relatório de Monitorização Gabinete de Monitorização do Plano de Gestão do Centro Histórico do Porto Património Mundial. Porto. Portugal, Sociedade de Reabilitação Urbana, 2011.

PORTO VIVO SRU. Projeto Base de Documento Estratégico para a Unidade de Intervenção São João. Porto. Portugal, Sociedade de Reabilitação Urbana, 2008.

Prefeitura Municipal de Ouro Preto MG (2018). Disponível em: <http://www.ouropreto.mg.gov.br/historia $>$. Acesso em 20 jan. 2018.

Prefeitura do Porto (2018). Disponível em: <http:// www.cm-porto.pt>. Acesso em 20 fev. 2018.

REIS FILHO, Nestor Goulart. Quadro da Arquitetura no Brasil. São Paulo: Ed. Perspectiva, 1997.

SANTOS, Ricardo. Princípios de desenho e forma na arquitectura portuguesa. $O$ ornamento como elemento de mediação: do plano da fachada para a abertura. Artigo, Workshop de Estudos Medievais da Universidade do Porto, 2013. 
VASCONCELOS, Sylvio de. Arquitetura no Brasil: Sistemas Construtivos. Belo Horizonte, Rona Editora, 1979.

WEHLING, Arno; WEHLING, Maria José C. De M. A formação do Brasil Colonial. Rio de Janeiro, Nova Fronteira,1994.
ZARROQUINO, Luís D. Evolução da casa no Brasil. Programa para Análise de Revalidação de Diplomas, Universidade Federal do Rio de Janeiro: 2006. 